ARTIGOS

\section{DISCLOSURE AMBIENTAL E RENTABILIDADE: UM ESTUDO COM EMPRESAS DO SETOR DE ELETRODOMÉSTICOS LISTADAS NA BOVESPA}

\section{RESUMO}

Esta pesquisa tem como objetivo analisar seis empresas no ramo de eletrodomésticos listadas na BOVESPA com o intuito de identificar se elas trabalham a evidenciação ambiental e se este fator está ligado à sua rentabilidade. Para responder a tal pergunta, utilizou-se como metodologia a pesquisa do tipo descritiva, apresentando dados secundários das empresas de capital aberto no período de 2010 a 2014, do setor de área de eletrodomésticos. Foram selecionadas seis empresas: Brasmotor, IGB Eletrônica, Magazine Luiza, Springer, Via Varejo e Whirlpool, classificadas no setor de atuação pela BOVESPA. Como resultado, entendeu-se que, entre as seis empresas pesquisadas, não há relações significativas entre a evidenciação ambiental e sua rentabilidade, tendo em vista que algumas empresas que não publicaram dados ambientais tiveram rendimentos significativos. Conclui-se que não há uma necessidade de que as empresas divulguem informações mais precisas sobre o meio ambiente, tendo em vista que isso não influi em sua rentabilidade.

Palavras-chave: Evidenciação ambiental. Disclosure. Meio ambiente.

\section{INTRODUÇ̃̃̃O}

As transformações depreciativas causadas pelo homem no nosso ecossistema são evidentes e inúmeros fatores contribuem para a composição deste cenário, como o extrativismo mineral, a poluição advinda das indústrias, o crescimento desenfreado do consumo, entre outros pontos. As últimas décadas foram marcadas por modelos de produção em grande escala que desconsideram os aspectos ambientais, pois o lucro é a preocupação central das organizações.

Esses modelos de produção em massa que ajudaram a promover imensas mudanças no mundo tiveram sua ascensão no período da Revolução Industrial. Nessa época, as organizações não tinham a preocupação em relação ao esgotamento dos recursos naturais. Porém, com o passar dos anos, as discussões sobre o assunto ampliaram-se surgindo a necessidade de um modelo sustentável, no qual as organizações em suas áreas de atuação minimi- 
zem seus impactos sobre o meio ambiente.

Além dos problemas ecológicos, outros pontos são relevantes para os gestores das organizações: no Brasil, como também, em muitos outros países, as empresas têm que lidar com as próprias leis. Aqui no nosso País, existem leis específicas para a proteção do meio ambiente, como a Lei $\mathrm{N}^{0} 9.605$, de 12 de fevereiro de 1998, que trata de sanções penais e administrativas derivadas de condutas e atividades lesivas ao meio ambiente. Nesse aspecto jurídico, para evitar indesejáveis multas, acentua-se a necessidade das empresas em se preocupar na promoção de métodos ou modelos de gestão baseados na sustentabilidade ambiental. $\mathrm{O}$ acréscimo da conscientização em relação aos aspectos sociais e ambientais é percebido pelo crescimento do nível de divulgação voluntária e evidenciação das informações de natureza social e ambiental por parte das empresas (ROVER; SANTOS, 2013).

Segundo Dahlsrud (2008), os negócios devem, cada vez mais, ir além do aspecto produtor de riqueza, devendo-se preocupar com as dimensões sociais, econômicas e ambientais. Dessa forma, as ações de responsabilidade social e ambiental e a gestão do negócio não devem ser vistas de forma antagônica, mas, sim, atuar de forma a se complementarem. Nessa perspectiva, o disclosure ou evidenciação do meio ambiente torna-se uma realidade do mercado atual; cresce cada vez mais a conscientização individual do contexto ambiental na sociedade contemporânea. Nessa percepção, entende-se que os gestores devem desenvolver estratégias de mercado como vantagens competitivas que poderão elevar o nível de competitividade mercadológica, e também desenvolver, de forma geral, suas organizações, acentuando, assim, os lucros (RUFINO; MACHADO, 2017).

Apesar das sérias dificuldades decorrentes dessa problemática ambiental, ela desenvolve uma gama de oportunidades de negócios, pois hoje já existem empresas especializadas em consultoria ambiental. É importante observar que, nesse contexto, os gestores com estratégias mercadológicas eficientes poderão desenvolver uma forma de diferenciação de mercado, além de abrir novos nichos de ação.

Em decorrência do alto nível de competitividade do mercado, as empresas devem mostrar-se dispostas em buscar novas formas criativas de competir, agregando, assim, essas vantagens competitivas advindas desses diferenciais de mercado. Nesse sentido, a proposição principal desta pesquisa é o questionamento: Empresas do setor de eletrodomésticos que apresentam maior grau de evidenciação ambiental possuem rentabilidade superior? O objetivo estipulado para ajudar a responder à problemática deste trabalho é mostrar a relação entre as divulgações de informações ambientais e a rentabilidade da empresa. Entende-se, inicialmente, que a empresa, ao evidenciar a questão ambiental, obtém da sociedade uma melhor imagem. Entende-se que, quando isso ocorre, pode haver uma maior preferência por parte dos consumidores por produtos dessas empresas.

Percebeu-se na literatura uma lacuna da análise por setor específico de atividade no que se refere ao nível de disclosure ambiental e sua relação com a rentabilidade das empresas. Dessa forma, essa pesquisa contribui ao avaliar de forma isolada um determinado setor de atividade ao passo que a literatura pesquisada consta uma gama de trabalhos avaliando de forma conjunta o disclosure ambiental.

\section{FUNDAMENTAÇÃO TEÓRICA}

\subsection{DEFINIÇÃO DE EVIDENCIAÇÃO AMBIENTAL OU DISCLOSURE}

A Evidenciação Ambiental, conhecida também por Environamental disclosure, pode ser entendida como a exposição dos direitos e dos deveres a que uma empresa visa para ressaltar o atendimento dos direitos da sociedade (BRANCO et al., 2010). A convivência entre a empresa e o meio ambiente muda de uma para outra; cada empresa estabelece seu contexto e como irá atuar diante da sociedade (FREEDMAN; STAGLIANO, 2008).

A Evidenciação Ambiental também pode ser vista como uma ação educativa, na qual a 
organização e a sociedade estão em constante contato, buscando sempre um maior planejamento, o controle dos recursos disponíveis no meio ambiente, bem como uma ferramenta de prestação de contas junto à sociedade (ROSA et al., 2011).

Para Rufino e Machado (2017), as empresas perceberam a necessidade de inserir aspectos sociais e ambientais em suas perspectivas de negócios devido à percepção de que existe uma conscientização e cobrança por parte dos stakeholders. No Brasil, a divulgação ainda é voluntária, porém muitas empresas já têm essa preocupação na divulgação de suas ações de caráter ambiental e social, o que tem levado pesquisadores a buscar identificar a razão pelo qual o fenômeno acontece (ROVER; SANTOS, 2013).

Devido a este impacto positivo da Evidenciação Ambiental para a sociedade, os futuros investidores precisam ter confiança em seus investimentos. Nesse sentido, a disclosure trabalha na divulgação de informações para a sociedade, com o objetivo de informar àqueles que têm interesse em investir. $\mathrm{O}$ verdadeiro intuito é mostrar informações relevantes que possam transmitir segurança e confiança àqueles que pretendem investir em uma empresa (MELO; PONTE; OLIVEIRA, 2007; GONÇALVES; PIRANI; BORGER, 2007).

A partir de uma perspectiva informacional, a evidenciação das informações ambientais visa prover aos usuários externos informações relevantes para a tomada de decisão. Modelos de negócio transparentes passam a ser os preferíveis de futuros investidores, pois saber onde se está investindo é importante no mundo dos negócios.

\subsection{EVIDENCIAÇÃO AMBIENTAL}

Segundo a classificação de Verrecchia (2001) sobre a classificação das pesquisas sobre diclousure ambiental, pode-se destacar que as pesquisas que abordam o diclousure devem estar entre três categorias: A primeira denominada de pesquisa sobre Divulgação Baseada em Associação (association-based disclosure), que analisa a associação entre o disclousure voluntário e o comportamento dos acionistas. A segunda categoria é conhecida como pesquisa sobre Divulgação Baseada em Julgamento (discretionary-based disclosure) que investiga as razões que impulsionam os gestores a divulgar determinada informação. E a terceira categoria é nomeada de pesquisa sobre Divulgação Baseada em Eficiência (efficiency-based disclosure) que "inclui os trabalhos que investigam quais configurações de divulgação são as preferidas, na ausência de conhecimento passado sobre a informação." (BRAGA; SALOTTI, 2008, p. 5).

Pode-se observar com mais detalhes de acordo com Verrecchia (2001) que a primeira categoria, denominada de Divulgação Baseada em Associação (association-based disclosure), abrange pesquisas que visam averiguar a afinidade ou associação que relacionam a divulgação e as reações dos investidores diante delas. As reações dos investidores estão intrínsecas a seus investimentos no mercado de capitais, tornando-se o principal vilão de suas próprias riquezas. Nesta categoria, a divulgação é associada ao processo exógeno. Ainda que a essência da pesquisa esteja relacionada às consequências da divulgação nas reações dos investidores diante do equilíbrio na conduta dos preços e na quantidade de negócios.

A segunda categoria, denominada de Divulgação Baseada em Julgamento (discretionary-based disclosure), envolve pesquisas que mostram os argumentos para a realização da divulgação. Nesta categoria, é possível analisar os critérios que determinam a divulgação das informações por parte dos gestores e/ou empresas. Essa parte da veiculação é associada ao processo endógeno, pois a divulgação é estimulada pelos próprios gestores e/ou as empresas, ainda que, nesta segunda parte, o exclusivo consumidor das informações divulgadas seja o mercado de capitais.

A terceira categoria, denominada de Divulgação Baseada em Eficiência (efficiency-based disclosure), inclui pesquisas sobre as divulgações escolhidas, sem conhecimento transmitido pela divulgação passada; logo, não 
houve a informação, caracterizando-se, assim, como ex ante. Trabalhos realizados nessa categoria abordam os mais eficientes tipos de divulgação, ainda que nela seja elevada ao máximo a riqueza endógena por meio de ações dos agentes no mercado de capitais.

De acordo com Verrecchia (2001), as categorias de pesquisa são divididas em três tipos, e cada uma com suas correspondentes características de divulgação. Pode-se observar que duas delas apresentam um processo de divulgação com base na realização de uma pesquisa, seja ela por meio de associação ou julgamento; e outra categoria difere das duas anteriores (associada e julgamento) por realizar um levantamento de dados referente à qual tipo de divulgação é preferível antes de seu acontecimento. Com isso, a Categoria de Pesquisa em Eficiência almeja alcançar o valor máximo de eficiência com a exposição de divulgações preferenciais de informação, dando o poder de barganha para tomar a melhor decisão.

\subsubsection{Evidenciação ambiental nas empre- sas brasileiras}

Em outros países, também se observa uma crescente preocupação com a evidenciação de informações de natureza ambiental. Por exemplo, novas regras introduzidas no disclosure ambiental no Japão requerem que as companhias informem os riscos materiais ambientais que poderão vir a causar à descontinuidade da empresa. De acordo com Kawamura (apud CHAN-FISHEL, 2003, p. 5):

As regras novas exigem não só informações financeiras diretas, mas incluem também a provável deterioração de imagem da marcada companhia. Isto porque se a impropriedade de uma companhia afeta seu Corporate Social Responsibility (CSR), esta enfrenta o risco não só de sanções legais, mas de sanções do mercado e da sociedade; quer dizer, de uma reação adversa dos parceiros empresariais e consumidores.
No âmbito nacional, quanto aos estudos explicativos que tratam dos determinantes da divulgação social e ambiental, menciona-se a pesquisa de Dantas et al. (2016) que investigou o nível de evidenciação ambiental e social nas empresas com melhor desempenho no Índice de Sustentabilidade Empresarial (ISE), o qual identificou um baixo nível de disclosure ambiental e social, mesmo entre as empresas que possuem alto valor no ISE. A pesquisa realizada por Cunha e Ribeiro (2006) investigou os fatores que determinavam a publicação do Balanço Social por empresas listadas na Bolsa de Valores de São Paulo (BOVESPA) nos anos de 2003 e 2004. Os resultados evidenciaram que a divulgação voluntária de informações de natureza social está associada, positivamente, ao nível de governança corporativa e à divulgação em período anterior, e, negativamente, ao tamanho (ROVER et al., 2008).

Nas pesquisas realizadas para este trabalho, encontrou-se Rover, Borba e Murcia (2009), que buscam identificar as características do disclosure voluntário ambiental de empresas brasileiras, assim como em Rodrigues, Santos e Mello (2009), que analisam o disclosure ambiental da Petrobrás entre os anos de 1997 a 2007. Porém, ainda há poucos estudos no Brasil referentes a essa temática. Há, portanto, uma necessidade dos estudos dos prováveis benefícios dessa evidenciação para preencher algumas lacunas existentes sobre o tema. Segundo Lima (2009), entre os benefícios ocasionados pelo diclousure, pode-se destacar a redução tanto do custo de capital próprio quanto do custo de capital de terceiros.

\subsection{REPUTAÇÃO CORPORATIVA E DISCLOSURE}

No estudo do diclosure ambiental, é importante abordar conceitos sobre a reputação corporativa das organizações. A imagem da empresa está associada a uma reputação corporativa, e é essencial manter essa reputação positiva, para despertar interesse de investidores. Reputação corporativa, de acordo com 
Bromley (2002) e Sandberg (2002), é uma percepção social comum ou ainda um consenso sobre como a organização se comporta em dada situação. Isso se baseia em uma série de conceitos sobre as habilidades e ações da companhia para satisfazer os interesses dos vários stakeholders (HELM, 2007). Ainda segundo Roberts e Dowling (2002), a reputação corporativa pode ser definida como os atributos organizacionais, criados ao longo do tempo, que refletem o modo pelo qual os stakeholders veem a empresa como uma boa cidadã corporativa.

Segundo Modugu e Eboigbe (2017), no intuito de manter e melhorar a reputação corporativa, as empresas têm buscado ampliar o nível de disclosure ambiental e social. No entanto, tais autores informam que a variável tamanho da empresa tem-se caracterizado como um dos principais elementos definidores da quantidade e da qualidade do disclosure entre as empresas. Os autores acrescentam, também, que dois fatores têm contribuído no crescimento do processo de divulgação, são eles: a adoção das IFRS por parte dos países e a percepção, por meio de pesquisas empíricas, de que variáveis financeiras como endividamento, custo do capital próprio e rentabilidade têm sofrido influência do nível de evidenciação por parte das empresas.

\subsection{DISCLOSURE VERSUS RENTABI- LIDADE}

De acordo com o levantamento de dados realizados sobre a temática deste trabalho, pode-se observar que existem poucos que abordam essa relação disclosure versus rentabilidade. Desses trabalhos, podem-se destacar os autores Ahmed e Courtis (1999), que promoveram estudos tendo como objetivo buscar o controle e apontar as discrepâncias dos resultados encontrados em virtude da relação disclosure versus rentabilidade.

De acordo com Ahmed e Courtis (1999), as empresas justificam suas escolhas com base nas seguintes particularidades: custos dos proprietários, custos de agência, política de custos, custos judiciais, sinal e assimetria informacional, governança corporativa e controle, necessidade de capital e reputação da empresa de auditoria.
No valor contábil dos ativos, está intrínseco o tamanho da empresa, o número de acionistas, as receitas (entradas e saídas) e o valor de mercado de acordo com os estudos realizados por Ahmed e Courtis (1999) e Rover et al. (2008), entre outros. Outra questão analisada quanto à disclosure é a rentabilidade da firma. Como menciona Singhvi e Desai (1971, p. 138): "A maior lucratividade motiva gerenciamento e fornece mais informações porque ela aumenta a confiança dos investidores, o que, por sua vez, aumenta a compensação do gerenciamento." Para os autores, o gerenciamento é diretamente proporcional ao lucro da empresa; e quanto maior a entrada de receitas, maior será o investimento em divulgação de informações.

Segundo Rufino e Machado (2017), a responsabilidade social/ambiental é um tema em ascensão no ambiente corporativo. Isso se percebe devido à preocupação das empresas em divulgar suas ações nas áreas ambiental e social. Esse processo de divulgação tende, e alguns estudos apontam nessa direção, a se caracterizar como elemento de diferenciação entre as empresas, que, por sua vez, pode levar a aumento na rentabilidade, diminuição do custo do capital próprio e qualidade de seu endividamento; fato que é observado por Rover e Santos (2013) ao constatar que um nível elevado de divulgação socioambiental desfavorável aumentou o custo de capital próprio.

O investimento em divulgação de informações se destaca nas empresas mais rentáveis, diferenciando-as de outras que não apresentam tanta rentabilidade ou quase nenhuma (ROVER et al., 2008). Pode-se observar, também, que, de acordo com a literatura pesquisada, a existência da relação entre a transparência das informações e a rentabilidade (ROE) não é consenso entre os autores.

\section{METODOLOGIA}

\subsection{TIPOLOGIA DA PESQUISA}

A pesquisa realizada é classificada como descritiva, sem a pretensão de inferência ou 
confirmação, apresentando dados secundários das empresas de capital aberto no período de 2010 a 2014, do setor de área de eletrodomésticos, utilizando-se como base para a explicação dessa área poluidora o Anexo VIII da Lei $\mathrm{n}^{\mathrm{o}} .10 .165 / 2000$, que está relacionado à Política Nacional do Meio Ambiente. Foram selecionadas seis empresas, com embasamento em seu ramo de atuação, as quais foram classificadas no setor de atuação pela BOVESPA.

\subsection{COLETA DE DADOS}

Para a realização desta pesquisa, foi feita uma coleta de dados nas Demonstrações Financeiras Padronizadas (DFPs) e recorreu-se, também, aos Relatórios de Sustentabilidade (RS) para dar maior credibilidade e embasamento à pesquisa. Os relatórios foram levantados nos anos de 2010, 2011, 2012, 2013 e 2014, consultados no site da BOVESPA e nos sites das empresas exibidas na BOVESPA.

Para desempenhar a pesquisa sobre evidenciação ambiental, realizou-se a análise do conteúdo das informações selecionadas em grupo para facilitar o estudo e a conclusão das condições de produção/entradas das mensagens. Pode-se observar que, para realizar a análise das informações ambientais, foi cadastrado um registro quantitativo dos grupos analisados.

A composição conceitual foi abordada com base nos trabalhos de Rover et al. (2012) e Meneses (2011).

A composição conceitual contabilizou uma listagem de disclosure ambiental entre cada empresa abordada na análise do estudo realizado. Essa listagem é constituída de grupos e subgrupos, nos quais se calculou o percentual nos subgrupos. Logo, se 12 das 20 empresas analisadas apresentam a evidenciação, isso corresponderá a 60 pontos percentuais. Observa-se que o número de disclosure corresponde à variável dependente, que condiz com as características de cada empresa.

Além do índice de disclosure ambiental, foram coletados dados relativos ao desempenho financeiro das empresas, além de variáveis de con- trole: Tamanho e Rentabilidade e outras variáveis como a Sustentabilidade, os Serviços de Auditoria e a Publicação do RS utilizados na pesquisa.

\subsection{ELABORAÇÃO DAS HIPÓTESES DE PESQUISA}

Para formular este estudo, foi realizado um levantamento de características individuais de cada empresa. Para isso, levantaram-se cinco hipóteses para a realização dos estudos como: tamanho da empresa, rentabilidade, sustentabilidade e publicação do RS e serviços de auditoria.

\subsubsection{Tamanho da empresa}

O tamanho da empresa influencia diretamente em sua atuação, no local e nas regiões próximas, na qual ela está instalada, sofrendo, assim, influência e busca de pessoas interessadas, stakeholders, e de políticos visando promover a imagem de si e da empresa com política de boas ações. Para isso, este trabalho foi baseado na hipótese da Teoria Positiva da Contabilidade (WATTS; ZIMMERMAN, 1978). Como menciona Watts e Zimmerman (1978), o primeiro ponto da Teoria da Contabilidade está relacionado ao conjunto de dados que abordam a informação contábil e as informações de mercado, apresentando, assim, a receita ou retorno associado ao preço das ações ou o retorno competente. Já o segundo, o ponto da Teoria da Contabilidade, aborda os estudos para uso de accruals para modificar os resultados contábeis, incentivando os gestores a fazê-los. Com isso, a introdução da Teoria da Contabilidade e as consequentes ações geradas pelo uso e aplicação dessa teoria motivaram o surgimento do interesse por parte da área contábil nas áreas acadêmicas e profissionais. (LOPES; MARTINS, 2009).

H1: Empresas maiores divulgam mais informações ambientais que empresas menores.

\subsubsection{Rentabilidade}

A rentabilidade em face do nível de disclosure está associada ao gerenciamento de 
competências que tem como objetivo obter altos lucros, visando executar as atividades sempre na busca de atender aos acordos feitos com os stakeholders, apresentando informações ambientais convenientes com a Teoria da Legitimidade (COWEN; FERRERI; PARKER, 1987). As empresas que apresentam maior rentabilidade, consequentemente, tendem a realizar uma maior divulgação das informações ambientais com o intuito de se destacar perante as empresas que apresentam uma menor rentabilidade (AKERLOF, 1970).

H2: Empresas com maior rentabilidade divulgam mais informações ambientais que aquelas com menor rentabilidade.

\subsubsection{Sustentabilidade}

O indicador apresentado pela sustentabilidade visa apresentar o monitoramento e controle do desempenho das práticas sustentáveis das empresas, buscando o reconhecimento diante da sociedade. Como o estudo é voltado para empresas brasileiras, utilizou-se como parametrização o Índice de Sustentabilidade Empresarial (ISE) e os dados apresentados no site da BOVESPA. Esse estudo foi realizado utilizando a variável binária, 0 ou 1, aplicando 1 para empresas presentes no grupo de ISE e 0 para empresas que não estão presentes nesse grupo.

H3: Empresas pertencentes ao ISE divulgam mais informações ambientais que aquelas que não pertencem ao grupo.

\subsubsection{Serviços de auditoria}

Os serviços de auditoria correspondem a acordos e contratos realizados entre os auditores e as partes interessadas, os clientes. Os auditores têm papel de influenciar os clientes na divulgação de informações, fortalecendo, assim, o papel da evidenciação diante da sociedade (ROVER et al., 2008). Como menciona Watts e Zimmerman (1978), os auditores têm a função de influenciar a publicação de informações, intensificando, assim, a ação da evidenciação no cenário da sociedade. Ainda que, para a realiza- ção desse estudo, utilizou-se a variável binária, 0 ou 1 , aplicando 1 para empresas auditadas e 0 em caso alternativo.

H4: Empresas auditadas por 'Big Four' divulgam mais informações ambientais que aquelas auditadas por outras empresas de auditoria.

\subsubsection{Publicação do RS}

A publicação do RS está relacionada com a apresentação dos Relatórios Ambientais e a divulgação dos índices ambientais. Observa-se, ainda, pouca publicação do RS por parte das empresas. Para operacionalizar esta variável, foi utilizada uma codificação binária, 0 ou 1; sendo o número 1 para indicar as empresas que divulgam relatórios ambientais e 0 para a não divulgação.

H5: Empresas que publicam Relatório de Sustentabilidade divulgam mais informações ambientais que aquelas que não publicam.

\subsection{TÉCNICA DE ANÁLISE}

Para análise dos dados, foram utilizados testes não paramétricos, que são adequados para os testes de hipóteses em distribuições não normais e/ou pequenas amostras. $\mathrm{O}$ teste Kruskal-Wallis foi usado para averiguar se as variáveis métricas (rentabilidade e tamanho da empresa) variam em relação aos graus de evidenciação ambiental das empresas; e o teste qui-quadrado foi usado para averiguar se há associação entre as variáveis categóricas (ISE, Auditoria, possui RS) e o grau de evidenciação ambiental das empresas.

O teste Kruskal-Wallis, segundo Hackbarth Neto e Stein (2003), deve ser aplicado quando se comparam três ou mais grupos independentes e a variável deve ser a de mensuração ordinal. Ele indica se há diferenças entre, pelo menos, dois grupos, utilizando valores numéricos transformados em postos e agrupados em um conjunto de dados.

A realização do teste Kruskal-Wallis consiste em atribuir a cada valor observado um posto. Para o menor valor, menor posto, maior valor, 
utiliza-se maior posto (HACKBARTH NETO; STEIN, 2003). Quando as amostram forem menor que 6 e os grupos $\leq 5$, recorre-se, segundo Hackbarth Neto e Stein (2003), a tabelas especiais que são com valores críticos da distribuição $\mathrm{H}$ de Kruskal_Wallis. Outro teste utilizado nesta pesquisa é o Qui-quadrado, sendo necessário calcular os graus de liberdade. É aplicado, também, quando se comparam dois ou mais grupos independentes não necessariamente do mesmo tamanho (HACKBARTH NERO; STEIN, 2003).

\section{APRESENTAÇÃO E ANÁLISE DOS RESULTADOS}

Foram analisadas seis empresas que representam todo o setor de eletrodomésticos com ações negociadas na Bolsa de Valores brasileira: Brasmotor, IGB Eletrônica, Magazine Luiza, Springer, Via Varejo e Whirlpool. Antes dos testes de hipóteses, buscou-se caracterizar as empresas objeto de análise desta pesquisa.

A Brasmotor S.A. era proprietária da Brastemp, porém, uniu-se à Consul e à Semer e hoje controla a maior indústria da linha branca da América Latina. Sobre a IGB Eletrônica, sabe-se que é a nova denominação da Gradiente Eletrônica S.A.; a empresa passou por um pe- ríodo de crise, entrando em processo de recuperação a partir de 2007 e voltando ao mercado brasileiro no primeiro semestre de 2012. A Magazine Luíza é uma empresa brasileira com sede em Franca, São Paulo e é a nona maior empresa varejista do País. A Springer foi criada em 1934, no Rio Grande do Sul, é uma das pioneiras no ramo da refrigeração e está presente em todo o Brasil. A Via Varejo foi fundada em 2010, após a fusão de duas grandes empresas varejistas que são as Casas Bahia e a Pontofrio. A Whirlpool é uma das maiores fabricantes mundiais de eletrodomésticos com mais de setenta centros de produção e pesquisa.

\subsection{DESCRIÇÃO GERAL DOS RESUL- TADOS}

A Evidenciação Ambiental varia de empresa para empresa, podendo ser considerada um processo educativo, como bem afirmam Borges, Rosa e Ensslin (2010). Pode-se também afirmar que, a partir dela, a sociedade e as organizações permanecem em constante comunicação e aprendizagem. Nesse sentido, pode-se verificar, no quadro 1 a seguir, o percentual de evidenciação ambiental conforme o item analisado.

\begin{tabular}{|l|l|l|}
\cline { 2 - 3 } \multicolumn{1}{l|}{} & Contagem & $\%$ \\
\hline Declaração das políticas/práticas/ações atuais e futuras & 7 & $23 \%$ \\
\hline Estabelecimento de metas e objetivos ambientais & 7 & $23 \%$ \\
\hline $\begin{array}{l}\text { Declarações indicando que a empresa está (ou não) em obediência às leis, licenças, } \\
\text { normas e aos órgãos ambientais }\end{array}$ & 6 & $20 \%$ \\
\hline Reciclagem & 6 & $20 \%$ \\
\hline Uso eficiente/Reutilização da água/Tratamento de Efluentes & 6 & $20 \%$ \\
\hline Desenvolvimento/Exploração de novas fontes de energia & 6 & $20 \%$ \\
\hline Investimentos ambientais & 6 & $20 \%$ \\
\hline Relacionamento com stakeholders & 6 & $20 \%$ \\
\hline Auditoria Ambiental & 5 & $17 \%$ \\
\hline Gestão Ambiental & 5 & $17 \%$ \\
\hline Desperdícios/Resíduos & 5 & $17 \%$ \\
\hline Custos/Despesas ambientais & 5 & $17 \%$ \\
\hline Educação ambiental (internamente e/ou comunidade) & 5 & $17 \%$ \\
\hline Menção sobre sustentabilidade/Desenvolvimento Sustentável & 5 & $17 \%$ \\
\hline
\end{tabular}




\begin{tabular}{|l|l|l|}
\hline Parcerias ambientais & 4 & $13 \%$ \\
\hline Prêmios e participações em índices ambientais & 4 & $13 \%$ \\
\hline ISO 14.000 & 4 & $13 \%$ \\
\hline Reparo aos danos ambientais & 4 & $13 \%$ \\
\hline Utilização de materiais desperdiçados na produção de energia & 4 & $13 \%$ \\
\hline Discussão sobre a preocupação com a possível falta de energia & 4 & $13 \%$ \\
\hline Práticas contábeis ambientais & 4 & $13 \%$ \\
\hline Pesquisas relacionadas ao meio ambiente & 4 & $13 \%$ \\
\hline Projetos de Mecanismos de Desenvolvimento Limpo (MDL) & 4 & $13 \%$ \\
\hline Créditos de Carbono & 4 & $13 \%$ \\
\hline Gases do Efeito Estufa (GEE)/Emissões atmosféricas & 4 & $13 \%$ \\
\hline Processo de Acondicionamento (embalagens) & 1 & $3 \%$ \\
\hline Conservação e/ou utilização mais eficiente nas operações & 1 & $3 \%$ \\
\hline Desenvolvimento de produtos ecológicos & 0 & $0 \%$ \\
\hline Impacto na área de terra utilizada & 0 & $0 \%$ \\
\hline Odor & 0 & $0 \%$ \\
\hline Vazamentos e derramamentos & 0 & $0 \%$ \\
\hline Passivos Ambientais & 0 & $0 \%$ \\
\hline Seguro Ambiental & 0 & $0 \%$ \\
\hline Ativos ambientais tangíveis e intangíveis & 0 & $0 \%$ \\
\hline Certificados de Emissões Reduzidas (CER) & 0 & $0 \%$ \\
\hline Gerenciamento de florestas/Reflorestamento & 0 & $0 \%$ \\
\hline Conservação da biodiversidade & 0 & $0 \%$ \\
\hline Paisagismo e jardinagem (landscaping) & 0 & $0 \%$ \\
\hline
\end{tabular}

Quadro 1 - Percentual de evidenciação ambiental, por item evidenciado Fonte: dados da pesquisa (2016).

O Quadro 1 demonstra a quantidade de itens evidenciado nas seis empresas selecionadas no período de 5 anos, mais especificamente entre 2010 e 2014. É possível verificar que os dois elementos mais evidenciados foram a "Declaração das políticas/práticas/ações atuais e futuras" e o "Estabelecimento de metas e objetivos ambientais", ambos com $23 \%$ de evidenciação. Seguidamente, há "Declarações indicando que a empresa está (ou não) em obediência às leis, licenças, normas e aos órgãos ambientais", "Reciclagem", Uso eficiente/ reutilização da água/tratamento de efluentes", "Desenvolvimento/exploração de novas fontes de energia", "Investimentos ambientais" e "Relacionamento com stakeholders" com 20\% de evidenciação. Uma informação importante é que dados como "Desenvolvimento de produtos ecológicos", Impacto na área de terra utilizada", "Odor", "Vazamentos e derramamentos", "Passivos ambientais", "Seguro Ambiental", "Ativos ambientais tangíveis e intangíveis", "Certificados de emissões reduzidas (CER)", "Gerenciamento de florestas/reflorestamento" "Conservação da biodiversidade" e "Paisagismo e jardinagem" não tiveram nenhuma evidência entre as cinco empresas campo desta pesquisa. Informações como essas são muito importantes no que diz respeito ao cuidado com o meio ambiente, principalmente quando se trata de vazamentos e derramamentos tendo em vista que esse tipo de acontecimento pode causar uma catástrofe ambiental.

Ainda em relação ao Quadro 1, ob- 
serva-se que as empresas Brasmotor, IGB Eletrônica e a Springer não apresentaram nenhuma evidência de ações ambientais no período analisado. Assim, é interessante observar que, segundo Borges, Rosa e Ensslin (2010), há uma tendência de grande parte das empresas demonstrar uma consciência ambiental. Conforme os autores, isso ocorre porque, quando uma instituição demonstra interesse e valorização com o meio ambiente, ela se torna mais valorizada perante a opinião pública (BORGES; ROSA; ENSSLIN, 2010).

É evidente que as empresas precisam dos stakeholders para manter seus inves- timentos. De tal modo, a opinião deles e a transparência por parte da empresa são pilares para a manutenção e o desenvolvimento de qualquer instituição empresarial. Destarte, pode-se observar tal consideração a partir da análise dos rendimentos das empresas investigadas, comparando as que apresentaram a evidenciação ambiental; no caso desta pesquisa, foram a Magazine Luíza, Via Varejo e Whirlpool, com as que não apresentaram a evidenciação de nenhum dos itens como a Brasmotor, IGB Eletrônica e Springer. Os dados financeiros das empresas para o período analisado foram tabulados e estão descritos na tabela 1 .

Tabela 1 - Dados financeiros das empresas (2010 à 2014)

\begin{tabular}{|c|c|c|c|c|c|c|c|}
\hline & Ano & BRASMOTOR & $\begin{array}{c}\text { IGB } \\
\text { ELETRÔNICA }\end{array}$ & $\begin{array}{l}\text { MAGAZINE } \\
\text { LUÍZA }\end{array}$ & SPRINGER & $\begin{array}{c}\text { VIA } \\
\text { VAREJO }\end{array}$ & WHIRLPOOL \\
\hline \multirow{5}{*}{$\stackrel{\text { In }}{0}$} & 0 & 35,55 & 2,88 & 1,93 & 1,79 & 1,82 & 37,06 \\
\hline & 1 & 20,89 & 13,31 & $-1,14$ & 31,25 & 10,75 & 20,49 \\
\hline & 2 & 28,53 & $-130,36$ & 16,40 & $-3,05$ & 28,99 & 28,94 \\
\hline & 3 & 33,99 & 6,99 & 17,11 & $-13,91$ & 19,89 & 33,31 \\
\hline & 4 & 34,99 & 8,38 & 146,81 & $-23,95$ & $-2,53$ & 33,47 \\
\hline \multirow{5}{*}{$\stackrel{0}{0}$} & 0 & 3,51 &,- 96 &, 02 &, 14 & ,09 & 1,33 \\
\hline & 1 & 2,07 &,- 39 &,- 01 & 2,17 &, 27 &, 71 \\
\hline & 2 & 2,83 & 3,43 & ,14 &,- 24 &, 85 & 1,03 \\
\hline & 3 & 3,38 & $-1,09$ &, 24 & $-1,15$ &, 59 & 1,25 \\
\hline & 4 & 3,48 & $-1,45$ & ,14 & $-1,80$ &,- 07 & 1,15 \\
\hline \multirow{5}{*}{ 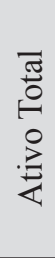 } & 0 & 8,94 & 7,21 & 10,79 & 7,30 & 11,67 & 10,78 \\
\hline & 1 & 8,98 & 8,99 & 10,94 & 7,63 & 11,70 & 10,87 \\
\hline & 2 & 9,14 & 7,66 & 11,30 & 7,43 & 11,81 & 11,00 \\
\hline & 3 & 9,28 & 7,66 & 10,88 & 7,24 & 11,98 & 11,09 \\
\hline & 4 & 9,11 & 7,64 & 10,78 & 7,16 & 11,49 & 11,03 \\
\hline
\end{tabular}

Fonte: dados da pesquisa (2016).

Observa-se que a Brasmotor foi a empresa que passou mais anos com maior Retorno sobre o Patrimônio Líquido (ROE), estando com os números entre os anos de 2011, 2013 e 2014 à frente das demais. Porém, é interessante destacar que, nos anos de 2010 e 2012, a Whirlpool obteve maior ROE e, nos anos de 2011, 2013 e
2014, o retorno foi pouco abaixo da Brasmotor. As empresas IGB Eletrônica, Magazine Luíza e Springer tiveram ROE muito baixo, e todas passaram por um período com saldo negativo. A IGB teve o saldo do retorno negativo no ano de 2012, a Magazine Luíza no ano de 2011, Via Varejo em 2014 e a Springer teve saldo abaixo 
de zero nos anos de 2012, 2013 e 2014, sendo a empresa que passou mais tempo com retorno negativo entre os anos pesquisados.

Em relação ao Retorno sobre o Investimento (ROI), as únicas empresas que não tiveram percentuais negativos foram a Brasmotor e a Whirlpool. Pode-se afirmar que as empresas analisadas tiveram pouca variação na evidenciação ambiental, no período analisado, conforme se observa no Gráfico 1:

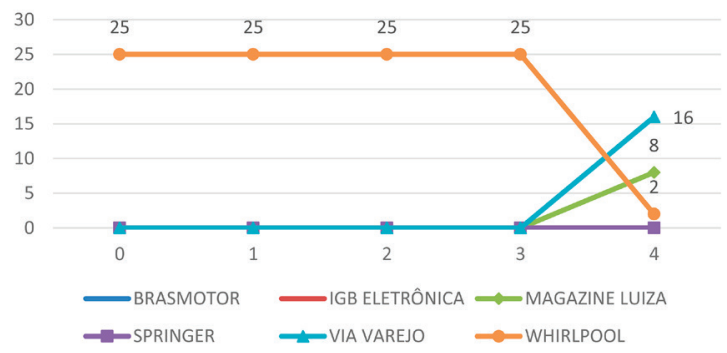

Gráfico 1 - Evolução do índice de disclosure ambiental, por empresa, no período estudado Fonte: dados da pesquisa (2016).

A associação entre as variáveis, ou seja, altos índices de disclosure não estão relativos à alta rentabilidade. De fato, os valores podem ser observados na primeira tabela aqui: o maior índice de disclosure está associado à ROE entre $20 \%$ e $37 \%$, enquanto o menor índice está associado a um ROE de $33 \%$.

Em relação à evolução da evidenciação ambiental no período analisado, observa-se que a Whirlpool, que apresentava maior grau de evidenciação nos três primeiros anos, tem um decréscimo a partir de 2013. Isso acontece pelo fato de que, diferentemente dos anos anteriores, em que havia um relatório anual, os anos 2013 e 2014 foram apresentados em apenas um relatório, resumindo as informações e, segundo o site da empresa (WHIRLPOOL, 2016), tornou-se mais breve, porém com relatos considerados mais relevantes. Os novos itens analisados nos anos de 2013 e 2014 foram os seguintes: gestão de resíduos, eficiência energética, gestão de água, produtos sustentáveis, Instituto Consulado da Mulher, Saúde e segurança do trabalho, mudanças climáticas, gestão estratégica da sustentabilidade, inovação sustentável e desenvolvimento profissional. Segundo a direção da Whirlpool, essa mudança ocorreu considerando critérios de interesse para os stakeholders e a relevância estratégica para a organização. Já a Brasmotor e a Magazine Luíza tiveram considerável aumento na evidenciação ambiental a partir de 2013. Considera-se que essas empresas passaram a ter mais responsabilidade no que concerne à divulgação desses dados, atendendo aspectos relevantes para a sociedade como a preservação ambiental. Assim, as seis empresas aqui analisadas foram, então, divididas em três grupos, de acordo com o índice de disclosure ambiental.

\begin{tabular}{|l|l|l|}
\hline Grupo & Grau de Evidenciação & Empresas \\
\hline 0 & Nulo & Brasmotor, Springer, IGB Eletrônica \\
\hline 1 & Baixo, Crescente & Via Varejo, Magazine Luíza \\
\hline 2 & Alto, Decrescente & Whirlpool \\
\hline
\end{tabular}

Quadro 2 - grau de evidenciação ambiental das empresas

Fonte: dados da pesquisa (2016).

O Quadro 2 demonstra o grau de evidenciação ambiental das empresas. De tal modo, a Brasmotor, Springer e IGB Eletrônica mantêm grau nulo, Via Varejo e Magazine Luíza têm grau baixo e, nos últimos anos, há um crescimento da evidenciação. Já a Whirlpool inicia com alto grau de evidenciação e, nos anos de 2013 e 2014, apresenta um decréscimo. Conforme Voss et al. (2012), as iniciativas voluntárias das empresas em evidenciar assuntos ambientais ocorrem, principalmente, em decorrência da opinião pública, grupos de pressão, setor financeiro e dificuldades na liberação da licença de operação. Considera-se que 
a opinião pública e as questões financeiras são os principais motivos para a decisão voluntária das empresas em questão.

\subsection{TESTE DAS HIPÓTESES}

Realizou-se o teste de Kruskal-Wallis para analisar se as empresas maiores divulgam mais informações ambientais que as menores. A hipótese nula testada é de que não há variação de tamanho entre os grupos de evidenciação ambiental. De acordo com o Quadro 3, a hipótese nula foi rejeitada, ou seja, há variação de tamanho entre os grupos. Os dados revelam que as empresas do grupo 0 são bem menores que as dos grupos 1 e 2 .

\begin{tabular}{|l|l|}
\hline$N^{0}$ de observações & 30 \\
\hline Estatística do teste & 22,243 \\
\hline Graus de liberdade & 2 \\
\hline Significância & 0,000 \\
\hline Decisão & Rejeitar hipótese nula. \\
\hline
\end{tabular}

Quadro 3 - Teste de Kruskal-Wallis

Fonte: dados da pesquisa (2016).

A segunda hipótese (H2) apresentada nesta pesquisa é a de que as empresas com maior rentabilidade divulgam mais informações ambientais que aquelas com menor rentabilidade. Sendo assim, segundo a análise, a distribuição do ROE não é estatisticamente diferente entre os grupos $(\mathrm{N}=30$; Estatística $=4,839 ; \mathrm{GL}=2$; sig. $=0,089)$, sendo possível rejeitar tal hipótese considerando que empresas que possuem maior rentabilidade não necessariamente divulgam mais informações ambientais. Um exemplo entre as organizações analisadas é a Brasmotor, que teve um dos maiores rendimentos, porém não apresentou informações ambientais no decorrer dos cinco anos pesquisados.

Diante desse resultado, anula-se a hipótese de que as empresas que possuem maior divulgação ambiental também têm maior rentabilidade. Ou seja, a Evidenciação Ambiental pode contribuir em outros critérios importantes para uma empresa, porém não tem muita influência quando se trata de rentabilidade.

A hipótese (H3) afirma que as empresas pertencentes ao Índice de Sustentabilidade Empresarial (ISE) divulgam mais informações ambientais que aquelas que não pertencem ao grupo. Assim, após pesquisa, verificou-se que apenas a Magazine Luíza, Via Varejo e Whirlpool pertencem ao ISE (Quadro 4). Verifica-se, ainda, que as empresas que pertentem ao ISE apresentam maior índice de Disclosure Ambiental, porém, como ainda são poucos os itens evidenciados, há pouca diferença entre os grupos das demais empresas, como se pode verificar também no gráfico seguinte:

As empresas não pertencentes ao ISE tiveram Postos de Média $=12$, enquanto as empresas pertencentes ao ISE tiveram Postos de Média = 19. Os resultados estão resumidos a seguir:

\begin{tabular}{|l|l|l|l|l|}
\hline \multicolumn{2}{|c}{ Hipótese nula } & \multicolumn{2}{c|}{ Teste } & Decisão \\
\hline 1 & $\begin{array}{l}\text { A amplitude de Índice de Disclosure } \\
\text { Ambiental é a mesma entre as } \\
\text { categorias de ISE. }\end{array}$ & $\begin{array}{l}\text { Teste de Mediana de amostras } \\
\text { independentes }\end{array}$ & $\begin{array}{l}\text { Rejeitar a hipótese } \\
\text { nula. }\end{array}$ \\
\hline 2 & $\begin{array}{l}\text { A distribuição de Índice de } \\
\text { Disclosure Ambiental é a mesma } \\
\text { entre as categorias de ISE. }\end{array}$ & $\begin{array}{l}\text { Teste U de Mann-Whitney de } \\
\text { amostras independentes }\end{array}$ & $0,029^{1}$ & $\begin{array}{l}\text { Rejeitar a hipótese } \\
\text { nula. }\end{array}$ \\
\hline
\end{tabular}

Quadro 4 - Resultado do teste de Mann - Whitney

São exibidas significâncias assintóticas. O nível de significância é 0,5 .

${ }^{1}$ A exata significância é exibida para este teste.

${ }^{2} \mathrm{Sig}$. Exata de Fisher

Fonte: dados da pesquisa (2016). 
Desse modo, convém afirmar que a terceira hipótese pode ser rejeitada, pois a diferença entre os níveis de significância é muito baixa, ou seja, as empresas pertencentes ao ISE tiveram pouca diferença em relação ao Disclosure Ambiental em relação às empresas não pertencentes a este grupo.

A quarta hipótese $(\mathrm{H} 4)$ diz respeito às empresas auditadas por 'Big Four'; porém, essa hipótese foi descartada mesmo antes de ser testada, já que nenhum dos estabelecimentos aqui estudados foram auditados pelas quatro maiores empresas contábeis especializadas em auditoria EY, PwC, Deloitte e KPMG.

A quinta hipótese (H5) é que as empresas que publicaram o Relatório de Sustentabilida- de divulgam mais informações ambientais que aquelas que não as publicam. No teste (Quadro 5), verifica-se que as empresas que publicam relatório de sustentabilidade divulgam mais informações ambientais. Nesse caso, há pouca diferença entre os grupos de empresas que divulgam o RS e as que não o divulgam. Os testes entre as empresas que divulgam RS demonstraram que há uma diferença entre as seis empresas analisadas, tendo em vista que a Brasmotor e a IGB Eletrônica não apresentam RS e também não dispõem de nenhuma informação ambiental. Porém, pode-se afirmar que o índice de diferença entre tais empresas é insignificante, podendo ser resumido na tabela a seguir:

\begin{tabular}{|c|c|c|c|c|}
\hline & Hipótese nula & Teste & Sig. & Decisão \\
\hline 1 & $\begin{array}{l}\text { A amplitude de Índice de Disclosure Ambiental é a } \\
\text { mesma entre as categorias de RS. }\end{array}$ & $\begin{array}{l}\text { Teste de Mediana de } \\
\text { amostras independentes }\end{array}$ &, $064^{1,2}$ & $\begin{array}{l}\text { Reter a } \\
\text { hipótese } \\
\text { nula. }\end{array}$ \\
\hline 2 & $\begin{array}{l}\text { A distribuição de Índice de Disclosure Ambiental é a } \\
\text { mesma entre as categorias de RS. }\end{array}$ & $\begin{array}{l}\text { Teste U de Mann- } \\
\text { Whitney de amostras } \\
\text { independentes }\end{array}$ & 0,1311 & $\begin{array}{l}\text { Reter a } \\
\text { hipótese } \\
\text { nula. }\end{array}$ \\
\hline
\end{tabular}

Quadro 5 - Resultado do teste de Mann - Whitney

São exibidas significâncias assintóticas. O nível de significância é 0,5.

${ }^{1}$ A exata significância é exibida para este teste.

${ }^{2}$ Sig. Exata de Fisher

Fonte: dados da pesquisa (2016).

Tendo em vista que são exibidas significâncias assintóticas, ou seja, que os níveis de Disclosure Ambiental são bem próximos entre os dois grupos de empresas, esta hipótese se torna nula, e pode-se admitir que não há diferença de grau de evidenciação entre as empresas que divulgam ou não os relatórios de sustentabilidade.

\section{CONSIDERAÇÕES FINAIS}

Analisar o nível de Evidenciação Ambiental de uma empresa não é fácil. Isso foi verificado no decorrer desta pesquisa tendo em vista a grande dificuldade de se encontrar informações ambientais das seis empresas aqui pesquisadas. Essa dificuldade demonstra, de certo modo, duas tendências. A primeira diz respeito à falta de interesse por parte destas empresas de informar seus dados ambientais. A segunda sugere que as empresas pesquisadas não apresentam ações de reparação/compensação/ manutenção do meio ambiente o quanto deveriam, uma vez que utilizam recursos ambientais como matéria prima.

Os resultados obtidos demonstram que, das seis empresas, quatro apresentaram relatórios ambientais; porém, estes não continham todas as informações importantes no que diz respeito à Evidenciação Ambiental. Entre os itens de maior evidenciação, pode-se destacar a "Declaração das políticas/práticas/ações atuais e futuras" e o "Estabelecimento de metas e objetivos ambientais".

É importante destacar aqui que foram apresentadas cinco hipóteses relacionando o 
nível de Disclosure Ambiental a questões como o tamanho da empresa, rentabilidade, sustentabilidade, serviços de auditoria e publicação de RS. Destas, cinco hipóteses testadas estão nulas tendo em vista que a evidenciação não se relaciona com nenhum desses itens apresentados. Esse fato leva a concluir que não há um nível de interesse tanto por parte das empresas quanto por parte dos stakeholders e da sociedade de forma geral, pois a Brasmotor, IGB Eletrônica e Springer, por exemplo, estão entre as instituições analisadas com menos divulgação de informações ambientais, porém com rentabilidades significativas.

Foi possível verificar, por meio da análise dos dados da pesquisa, que as empresas estão mais voltadas para divulgar que estão preocupadas com o meio ambiente do que mesmo informar e manter atualizadas informações importantes sobre como elas se estão relacionando com o meio ambiente. Essa omissão gera, portanto, curiosidade em saber se estão cumprindo o que rege a legislação ambiental.

As limitações deste trabalho se referem, principalmente, ao tamanho da população pesquisada, que permite um estudo descritivo e que não tem pretensão de generalizações ou inferências. Para novos estudos, sugere-se a realização de pesquisas que comparem estas variáveis em setores intensivos em uso de recursos ambientais.

\section{DISCLOSURE ENVIRONMENTAL AND PROFITABILITY: A STUDY ON COMPANIES IN THE SECTOR OF HOME APPLIANCES LISTED IN BOVESPA}

\begin{abstract}
This research aims at analyzing six companies in the home appliance industry listed in BOVESPA, identifying whether they work with environmental disclosure and whether this factor is linked to their profitability. To answer such question we used as research descriptive as a methodology, presenting secondary data relating to public companies of the home appliance sector in the period stemming from 2010 to 2014. Six companies were selected: Brasmotor, IGB Eletrônica, Magazine Luiza, Springer, Via Varejo and Whirlpool, all of which are classified in the aforementioned industry sector by BOVESPA. The result of the research established that among the six companies surveyed there is no significant relationship between environmental disclosure and profitability, given that some of the companies do not publish environmental data and had significant income. We, therefore, concluded that there is no need for the companies to disclose more accurate information relating to the environment, since that it does not affect their profitability.
\end{abstract}

Keywords: Environmental Disclosure. Disclosure. Environment. 


\section{DISCLOSURE AMBIENTAL Y RENTABILIDAD: UN ESTUDIO CON EMPRESAS DEL SECTOR DE ELECTRODOMÉSTICOS LISTADAS EN BOVESPA}

\section{RESUMEN}

Esta investigación tiene por objetivo analizar seis empresas en el ramo de electrodomésticos listadas en BOVESPA, identificando si ellas trabajan con disclosure ambiental y se ese hecho está relacionado a su rentabilidad. Para contestar a esa pregunta, se utilizó como metodología la investigación descriptiva, presentando datos secundarios de las empresas de capital abierto del sector de los electrodomésticos, en el periodo de 2010 a 2014. Seis empresas fueron seleccionadas: Brasmotor, IGB Eletrônica, Magazine Luiza, Springer, Via Varejo e Whirlpool, clasificadas en el mencionado sector por BOVESPA. Como resultado, se entendió que entre las seis empresas investigadas no hay relaciones significativas entre la disclosure ambiental y la rentabilidad, teniendo en cuenta que algunas empresas que no publicaron datos ambientales tuvieron rendimientos significativos. Se concluye que no hay una necesidad de que las empresas divulguen informaciones más precisas sobre el medio ambiente, teniendo en cuenta que esto no influencia su rentabilidad.

Palabras-clave: Disclosure ambiental. Disclosure. Medio ambiente.

\section{DISCLOSURE ENVIRONNEMENTAL ET RENTABILITE : UNE ETUDE SUR DES ENTREPRISES DU SECTEUR D'ELECTROMENAGERS LISTÉES AUPRÈS DE BOVESPA}

\section{RESUME}

Cette recherche a pour objectif l'analyse de six entreprises du secteur électroménager listées auprès de BOVESPA pour identifier si elles travaillent le disclosure environnemental et si cette pratique est liée à leur rentabilité. Pour répondre à cette question, nous avons utilisé la recherche descriptive comme méthdologie, en présentant des donnés secondaires des entreprises de capital ouvert du secteur électroménager dans la période de 2010 à 2014. Nous avons sélectionné six entreprises : Brasmotor, IGB Eletrônica, Magazine Luiza, Springer, Via Varejo et Whirpool, classées comme appartenant au susmentionné secteur par BOVESPA. Comme résultat, nous avons identifié que parmis les entreprises étudiées il n'y a pas de relations significatives entre le disclosure environnemental et la rentabilité, vu que certaines entreprises qui n'ont pas divulgé des informations environnementales ont eu des recettes significatives. La conclusion de l'article est qu'il n'est pas strictement nécessaire que les entreprises divulgent des informations plus précises sur l'environnement, puisque ceci n'a pas d'influence sur leur rentabilité.

Mots-clés: Disclosure environnemental. Disclosure. Environnement. 


\section{REFERÊNCIAS}

AHMED, K.; COURTIS, J. K. Association between corporate characteristics and disclosure levels in annual reports: a meta analysis. British Accounting Review, Kindlinton, n. 31, p. 35-61, 1999.

AKERLOF, G. The market for "lemons": quality, uncertainty and market mechanism. The Quarterly Journal of Economics, Cambridge, v. 84 , n. 3, p. 488-500, 1970.

BRAGA, J. P.; SALOTTI, B. M. Relação entre nível de disclosure ambiental e as características corporativas de empresas no Brasil. In: CONGRESSO USP DE INICIAÇÃO CIENTÍFICA EM CONTABILIDADE, 5., 2008, São Paulo. Anais... São Paulo: EAC/FEA/USP, 2008. Disponível em: <http://www.congressousp.fipecafi.org/web/artigos82008/180.pdf $>$. Acesso: 15 fev. 2016.

BRANCO, M. C. et al. An analysis of intellectual capital disclosure by Portuguese companies. EuroMed Journal of Business, United Kingdom, v. 5, n. 3, p. 258-278, 2010.

BORGES, A. P.; ROSA, F. S.; ENSSLIN, S. R. Evidenciação voluntária das práticas ambientais: um estudo nas grandes empresas brasileiras de papel e celulose. Produção, Florianópolis, v. 20, n. 3, p. 404-417, 2010. Disponível em: $\quad<$ http://www.scielo.br/pdf/prod/v20n3/ AOP_200905058.pdf>. Acesso: 14 maio 2016.

BROMLEY, D. B. Comparing corporate reputations: league tables, quotients, benchmarks, or case studies? Corporate Reputation Review, United Kingdom, v. 5, p. 35-50, 2002.

CHAN-FISHEL, Michelle. SEC and social/ environmental accounting. Corporate Sunshine Working Group Bulletin, 2003. Disponível em: <http: ||www.corporatesunsnhine.org/ research/CSWGbulletin09-06.pdf $>$. Acesso em: 20 set. 2016.
COWEN, S. S.; FERRERI, L. B.; PARKER, L. D. The impact of corporate characteristics on social responsibility disclosure: a typology and frequency-based analysis. Accounting, Organizations and Society, United Kingdom, v. 12, n. 2, p.111-122, 1987.

CUNHA, J.; RIBEIRO, M. Divulgação voluntária de informações de natureza social: um estudo nas empresas brasileiras. In: ENANPAD, 30., 2006, Salvador. Anais... Brasília: ANPAD, 2006. 1 CD-ROM.

DAHLSRUD, A. How corporate social responsibility is defined: an analysis of 37 definitions.

Corporate social responsibility and environmental management, United States, v. 15, n. 1, p. 1-13, 2008.

DANTAS, P. A. et al. Nível de evidenciação dos indicadores ambientais e sociais sob a perspectiva da análise hierárquica de processos (ahp): um estudo exploratório nas empresas com melhor desempenho no índice de sustentabilidade empresarial (ise) em 2013. GEPROS. Gestão da Produção, Operações e Sistemas, Bauru, v. 11, n. 1, p. 1-28, 2016.

FREEDMAN, M.; STAGLIANO, A. J. Environmental disclosures: electric utilities and Phase 2 of the Clean Air Act. Critical Perspectives on Accounting, United States, v.19, n. 4, p. 466-486, 2008.

GONÇALVES, R. C. M. G.; PIRANI, D. C.; BORGER, F. G. Qualidade das informações sobre responsabilidade social divulgadas pelos bancos privados com ações listadas no índice de sustentabilidade empresarial da Bovespa. In: ENCONTRO NACIONAL DA ASSOCIAÇÃO DE PÓSGRADUAÇÃO E PESQUISA EM ADMINISTRAÇÃO, 31., 2007, Rio de Janeiro. Anais... Salvador: ANPAD, 2007. 1 CD-ROM.

HACKBARTH NETO, A. A.; STEIN, C. E. Uma abordagem dos testes não-paramétricos 
com utilização do excel. 2003. Disponível em: $<$ http://www.mat.ufrgs.br/ viali/estatistica/ mat2282/material/textos/artigo_11_09_2003. pdf >. Acesso: 15 maio 2016.

HELM, S. The role of corporate reputation in determining investor satisfaction and loyalty. Corporate Reputation Review, United Kingdom, v. 10, n. 1, p. 22-37, 2007.

LIMA, G. A. S. F. Nível de evidenciação $\times$ custo da dívida das empresas brasileiras. Revista Contabilidade \& Finanças, São Paulo, v. 20, n. 49, p. 95-108, jan./abr. 2009.

LOPES, A. B.; MARTINS, E. Teoria da contabilidade: uma nova abordagem. São Paulo: Atlas, 2009.

MELO, F. M. A.; PONTE, V. M. R.; OLIVEIRA, M. C. Análise das práticas de evidenciação de informações avançadas e não-obrigatórias nas demonstrações contábeis das empresas brasileiras. RCO - Revista de Contabilidade e Organizações, São Paulo, v. 1, n. 1, p. 30-42, set./dez. 2007.

MENESES, Anelise Florencio de. Evidenciação das demonstrações contábeis: estudo sob a óptica do processo de convergência das Normas de Contabilidade aplicadas ao setor público. 2011. 167 f. Dissertação (Mestrado em Administração e Controladoria) - Universidade Federal do Ceará, Faculdade de Economia, Administração, Atuária e Contabilidade, Programa de Pós-Graduação em Administração e Controladoria, Fortaleza, 2011.

MODUGU, K. P.; EBOIGBE, S. U. corporate attributes and corporate disclosure level of listed companies in nigeria: a post-ifrs adoption study. Journal of Finance and Accounting, v. 5, n. 2, p. 44-52, 2017.

ROBERTS, Peter W.; DOWLING, Grahame R. Corporate reputation and sustained superior financial performance. Strategic Management
Journal, United States, v. 23, n. 12, p. 10771093, 2002.

RODRIGUES, F. F.; SANTOS, R. B.; MELLO, M. C. B. Análise do disclosure ambiental da empresa petrobras no período 1997 a 2007. In: CONGRESSO USP DE CONTROLADORIA E CONTABILIDADE, 9., 2009, São Paulo. Anais... São Paulo: USP, 2009. Disponível em: $<$ http://www.congressousp.fipecafi.org/web/ artigos92009/364.pdf>. Acesso: 10 fev. 2016.

ROSA, F. S. et al. Gestão da evidenciação ambiental: um estudo sobre as potencialidade e oportunidade do tema. Engenharia Sanitária e Ambiental, Rio de Janeiro, v. 16, p. 157-166, 2011.

ROVER, S. et al. Divulgação de informações ambientais nas demonstrações contábeis: um estudo exploratório sobre o disclosure das empresas brasileiras pertencentes a setores de alto impacto ambiental. Revista de Contabilidade e Organizações, São Paulo, v.3, n.2, p. 53-72, maio/ago. 2008.

ROVER, S.; BORBA, J. A.; MURCIA, F. D. R. Características do Disclosure ambiental de empresas brasileiras potencialmente poluidoras: análise das demonstrações financeiras e dos relatórios de sustentabilidade do período de 2005 a 2007. Contextus: Revista Contemporânea de Economia e Gestão, Fortaleza, v. 7, n. 1, p. 23-36, jan./jun. 2009.

ROVER, S. et al. Explicações para a divulgação voluntária ambiental no Brasil utilizando a análise de regressão em painel R.Adm., São Paulo, v. 47, n. 2, p. 217-230, abr./maio/jun. 2012.

ROVER, S.; SANTOS, Ariovaldo. Disclosure socioambiental e custo de capital próprio de companhias abertas no Brasil. In: CONFERÊNCIA INTERAMERICANA DE CONTABILIDADE SOCIOAMBIENTAL，3., 2013, Belém. Anais... Belém: CSEAR, 2013. 
RUFINO, M. A.; MACHADO, M. R. Relação de dependência entre a divulgação voluntária social e ambiental e as características das empresas de capital aberto no Brasil. Revista Ambiente Contábil, Natal, v. 9. n. 1, p. 344-363, jan./jun. 2017.

SANDBERG, K. Kicking the tires of corporate reputation. Harvard Management Communication Letter, v. 5, p. 3-4, 2002.

SINGHVI, S. S.; DESAI, H. B. An empirical analysis of the quality of corporate financial disclosure. The Accounting Review, v. 46, n. 1, p. 129-138, 1971.

VERRECCHIA, R. E. Essays on disclosure. Journal of Accounting and Economics, Netherlands, v. 32, p. 97-180, 2001.

VOSS, B. L. et al. Evidenciação ambiental dos resíduos sólidos de companhias abertas no Brasil potencialmente poluidoras. In: ENCONTRO DAANPAD, 36., 2012, Rio de Janeiro. Anais... Rio de Janeiro: Anpad, 2012. Disponível em: $<$ http://www.scielo.br/pdf/rcf/v24n62/04.pdf $>$. Acesso: 14 maio 2016.

WATTS, R.; ZIMMERMAN, J. Towards a positive theory of the determination of accounting standards. The Accounting Review, v. 53, n. 1, p. 112-134, 1978.

WHIRLPOOL. Sobre o relatório. Disponível em: <http://projetos.riccari.com.br/clientes/whirlpool/sobre-o-relatorio $>$. Acesso: 15 maio 2016. 